\title{
A Produção Científica dos Programas de Pós-Graduação do Colégio de Ciência da Vida na Revista Brasileira de Cancerologia
}

https://doi.org/10.32635/2176-9745.RBC.2020v66n4.1381

\author{
The Scientific Production of the Post-Graduation Programs of the School of Science of Life of the Brazilian Journal of Cancerology \\ La Producción Científica de los Programas de Posgrado de la Facultad de Ciencias de la Vida en la Revista Brasileira de \\ Cancerologia
}

Mario Jorge Sobreira da Silva'; Anke Bergmann²

O Colégio de Ciências da Vida da Coordenação de Aperfeiçoamento de Pessoal de Nível Superior (Capes) reúne um total de 17 áreas de concentração pertencentes a três grandes áreas: Ciências Agrárias, Ciências Biológicas e Ciências da Saúde. Essas áreas de concentração, em dezembro de 2020, contemplam um total de 1.490 Programas de Pós-Graduação (PPG) e 2.406 cursos avaliados e reconhecidos ${ }^{1}$.

Entre 2013 e 2018, autores brasileiros publicaram mais de 280 mil artigos indexados na Web of Science (WoS) e mais de 60 mil artigos indexados em periódicos na Scientific Electronic Library Online (SciELO), que não são abordados na $\mathrm{WoS}^{2}$. Grande parte dessa produção científica é publicada nas áreas de concentração pertencentes ao Colégio de Ciências da Vida da Capes (aproximadamente 204 mil), oriunda, na maioria das vezes, das produçôes dos PPG.

Essa grande disseminação do conhecimento científico, por um lado, se deve aos critérios de avaliação dos PPG utilizados pela Capes, por outro, trata-se de importante instrumento de democratização do acesso ao conhecimento científico. Para tanto, a adoção de estratégias, pelos periódicos científicos, em prol do acesso e da ciência aberta, deve ser uma prioridade, para que a produção científica consiga execer real impacto social.

A Revista Brasileira de Cancerologia (RBC) ao longo da sua história tem buscado dar ênfase ao acesso aberto de publicação científica de qualidade realizada nos serviços de saúde ${ }^{3}$. A partir de 2018, com a sua reestruturaçãó, vem adotando diversas políticas com o intuito de se tornar, também, um importante veículo de divulgação científica dos PPG incluídos no Colégio de Ciências da Vida. Todos os esforços engendrados estão sendo reconhecidos.

No que tange ao acesso aberto, cabe destacar que, em 2020, a RBC foi indexada no Direct of Open Access Journals (DOAJ) e na base indexadora Sumários de Revistas Brasileiras (Sumários.org). A RBC segue trabalhando para atender aos critérios de indexação de outras importantes bases de dados nacionais e internacionais.

Em relação à origem das produções científicas publicadas na RBC em 2020, do total de 93 artigos, 64,4\% envolveram autores (docentes e/ou discentes) vinculados a 43 PPG, de todas as macrorregióes brasileiras. Outros pontos que merecem destaque é que, neste ano: a) tivemos quase 600 manuscritos submetidos; b) mantivemos o tempo médio entre submissão e publicação inferior a seis meses; c) ampliamos em $50 \%$ o número de artigos publicados no ano; d) aumentamos de dois para seis o número de editores-associados. Esses resultados têm importantes significados, pois demonstram a ampliação da disseminação do conhecimento na área da oncologia no país.

Por fim, aproveitamos este último editorial de 2020 para agradecer a todos, equipe e comitê editorial, revisores ad hoc, autores e leitores. A RBC espera continuar contribuindo para a disseminaçáo de conhecimentos inovadores e de qualidade. Essa expectativa aumenta com a criação do novo PPG do Instituto Nacional de Câncer José Alencar Gomes da Silva (INCA), o Programa de Pós-Graduação em Saúde Coletiva e Controle do Câncer (PPGCan) que se inicia em 2021.

'Editor-Associado da Revista Brasileira de Cancerologia (RBC). Chefe da Divisão de Ensino da Coordenação de Educação do Instituto Nacional de Câncer José Alencar Gomes da Silva (INCA). Rio de Janeiro (RJ), Brasil. E-mail: mario.silva@inca.gov.br. Orcid iD: https://orcid.org/0000-0002-0477-8595

${ }^{2}$ Editora-Científica da RBC. Pesquisadora da Divisão de Pesquisa Clínica da Coordenação de Pesquisa do INCA. Rio de Janeiro (RJ), Brasil. E-mail: abergmann@inca. gov.br. Orcid iD: https://orcid.org/0000-0002-1972-8777

Endereço para correspondência: Mario Jorge Sobreira da Silva. Rua Marquês de Pombal, 125, 30 andar - Centro. Rio de Janeiro (RJ), Brasil. CEP $20230-240$. E-mail: mario.silva@inca.gov.br 


\section{REFERÊNCIAS}

1. Coordenação de Aperfeiçoamento de Pessoal de Nível Superior. Plataforma Sucupira [Internet]. Versão 3.38.6. Brasília, DF: CAPES; c2016. Cursos Avaliados e Reconhecidos; [acesso 2020 dez 15]. Disponível em: https://sucupira.capes. gov.br/sucupira/public/consultas/coleta/programa/quantitativos/quantitativoAreaAvaliacao.jsf

2. Web of Science Group. A pesquisa no Brasil: promovendo a excelência [Internet]. Philadelphia: Clarivate Analytics; c2019 [acesso 2020 dez 15]. Disponível em: https://propp.ufms.br/files/2019/09/Pesquisa-no-Brasil.pdf

3. Siqueira ASE, Casado L, Bergmann A, et al. A disseminação de conhecimento científico e a qualidade da informação. Rev Bras Cancerol. 2019;65(1):e-00291. doi: https://doi.org/10.32635/2176-9745.RBC.2019v65n1.291

4. Bergmann A, Casado L, Siqueira ASE, et al. Reestruturando uma Revista Científica do SUS com base na agenda 2030. Rev Bras Cancerol. 2018;64(1):7-8. doi: https://doi.org/10.32635/2176-9745.RBC.2018v64n1.114 